\title{
EUFOREA Rhinology Research Forum 2016: report of the brainstorming sessions on needs and priorities in rhinitis and rhinosinusitis*
}

P.W. Hellings ${ }^{1,2,3}$, C.A. Akdis' ${ }^{4}$, C. Bachert ${ }^{3,5}$, J. Bousquet ${ }^{6}$, B. Pugin' Rhinology 55: 202-210, 2017

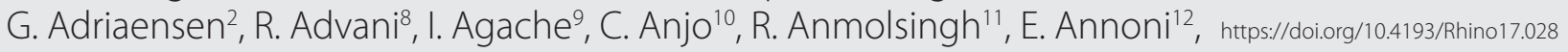
T. Bieber ${ }^{13}$, A. Bizaki ${ }^{14}$, I. Braverman ${ }^{15}$, I. Callebaut' ${ }^{1}$, J.A. Castillo Vizuete ${ }^{16}$, T. Chalermwatanachai ${ }^{3}$, R. Chmielewski ${ }^{17}$, C. Cingi' ${ }^{18}$, L. Cools' ${ }^{1}$, C. Coppije7, M.E. Cornet ${ }^{2}$, I. De Boeck ${ }^{19}$, E. De Corso ${ }^{20}$, G. De Greve', M. Doulaptsi ${ }^{21}$, *Received for publication: February 9, 2017 R. Edmiston 8 , S. Erskine 22, E. Gevaert' ${ }^{3}$, P. Gevaert ${ }^{3}$, K. Golebski2,23 , C. Hopkins²4, Accepted: February 10, 2017 V. Hox ${ }^{25}$, C. Jaeggi', G. Joos ${ }^{26}$, S. Khwaja ${ }^{27}$, A. Kjeldsen², L. Klimek ${ }^{29}$, M. Koennecke ${ }^{30}$, I. Kortekaas Krohn ${ }^{21}$, O. Krysko ${ }^{3}$, B.N. Kumar ${ }^{31}$, C. Langdon ${ }^{32}$, B. Lange ${ }^{27}$, G. Lekakis ${ }^{1,25}$, P. Levie ${ }^{33}$, E. Lourijsen², V.J. Lund ${ }^{34}$, K. Martens ${ }^{21}$, R. Mösges ${ }^{35}$, J. Mullol ${ }^{36}$, T.D. Nyembue ${ }^{37}$, S. Palkonen ${ }^{38}$, C. Philpott ${ }^{22}$, J. Pimentel ${ }^{39}$, A. Poirrier ${ }^{40}$, A.C. Pratas ${ }^{22}$, E. Prokopakis ${ }^{41}$, L. Pujols ${ }^{36}$, P. Rombaux ${ }^{25}$, C. Schmidt-Weber ${ }^{42}$, C. Segboer ${ }^{2}$, I. Spacova ${ }^{43}$, J. Staikuniene ${ }^{44}$, B. Steelant ${ }^{21}$, E.A. Steinsvik ${ }^{45}$, A. Teufelberger ${ }^{3}$, L. Van Gerven ${ }^{1,21}$, K. Van Gool ${ }^{46}$, R. Verbrugge ${ }^{47}$, B. Verhaeghe ${ }^{48}$, P. Virkkula ${ }^{49}$, S. Vlaminck ${ }^{50}$, E. Vries-Uss ${ }^{47}$, M. Wagenmann ${ }^{51}$, T. Zuberbier ${ }^{52}$, S.F. Seys ${ }^{7,21}$, W.J. Fokkens ${ }^{2}$

${ }^{1}$ Department of Otorhinolaryngology-Head and Neck Surgery, UZ Leuven, Belgium ${ }^{2}$ Department of Otorhinolaryngology, Academic Medical Center, Amsterdam, The Netherlands ${ }^{3}$ Upper Airways Research Laboratory, Department of Otorhinolaryngology-Head and Neck Surgery, Ghent University, Belgium ${ }^{4}$ Swiss Institute of Allergy and Asthma Research (SIAF), University of Zurich, Christine-Kühne Center for Allergy Research and Education, Davos, Switzerland

${ }^{5}$ Department of Otorhinolaryngology, Karolinska Institute, Stockholm, Sweden

${ }^{6}$ Department of Respiratory Disease, University Hospital Arnaud de Villeneuve, Montpellier, France

${ }^{7}$ European Forum for Research and Education in Allergy and Airway Diseases (EUFOREA), Brussels, Belgium ${ }^{8}$ Health Education North West, Manchester, UK

${ }^{9}$ Faculty of Medicine, Transylvania University, Brasov, Romania

${ }^{10}$ Department of Otorhinolaryngology, Hospital Sao José, Hospital Centre of Central Lisbon, Lisbon, Portugal

${ }^{11}$ Department of Otorhinolaryngology, Wigan Wrightington and Leigh NHS Foundation Trust, Wigan, UK

${ }^{12}$ Medtronic Inc.

${ }^{13}$ Department of Dermatology and Allergy, Christine Kühne-Center for Allergy Research and Education, Friedrich-Wilhelms-University, Bonn, Germany

${ }^{14}$ University of Tampere, Finland

${ }^{15}$ Hillel Yaffe Medical Center, Hadera Technion Faculty of Medicine, Haifa, Israel

${ }^{16}$ Respiratory Medicine, Hospital Universitario Quirón Dexeus, Barcelona, Spain

${ }^{17}$ Department of Otolaryngology, Military Institute of Aviation Medicine, Warsaw, Poland

${ }^{18}$ Department of Otolaryngology, Head and Neck Surgery, University of Eskisehir Osmangazi, Eskisehir, Turkey

${ }^{19}$ Department of Bioscience Engineering, University of Antwerp, Antwerp, Belgium

${ }^{20}$ Agostino Gemelli Hospital Foundation, Catholic University of the Sacred Heart, Head and Neck Surgery Area, Institute of Otorhinolaryngology, Rome, Italy 
${ }^{21}$ Laboratory of Clinical Immunology, KU Leuven, Belgium

${ }^{22}$ Norwich Medical School, University of East Anglia, UK

${ }^{23}$ Department of Experimental Immunology, Academic Medical Center, Amsterdam, The Netherlands

${ }^{24}$ ENT Departments, Guys and St Thomas Hospitals NHS Trust, London and James Paget University Hospital, Gorieston, United Kingdom

${ }^{25}$ Département d'Otorhinolaryngologie, Cliniques Universitaires Saint-Luc, Belgium

${ }^{26}$ Department of Respiratory Medicine, Ghent University, Belgium

${ }^{27}$ Department of Otolaryngology, University Hospital of South Manchester, Manchester, UK

${ }^{28}$ Department Of Otorhinolaryngology, Odense University Hospital, Denmark

${ }^{29}$ Center for Rhinology and Allergology, Wiesbaden, Germany

${ }^{30}$ University Hospital Schleswig-Holstein, Campus Lübeck, Department of Otorhinolaryngology, Lübeck, Germany

${ }^{31}$ Department of Otolaryngology-Head \& Neck, WWL NHS Foundation Trust and NIHR CRN, Greater Manchester, UK

${ }^{32}$ Rhinology Unit \& Smell Clinic, Department of Otorhinolaryngology, Clinical and Experimental Respiratory Immunology, IDIBAPS, Barcelona, Spain

${ }^{33}$ ENT Clinic Messidor, Brussels, Belgium

${ }^{34}$ Royal National Throat, Nose and Ear Hospital, University College London Hospitals, London, United Kingdom

${ }^{35}$ Faculty of Medicine, Institute of Medical Statistics, Informatics and Epidemiology, University of Cologne, Cologne, Germany

${ }^{36}$ Clinical \& Experimental Respiratory Allergy, IDIBAPS, CIBERES. Hospital Clinic, Universitat de Barcelona, Barcelona, Catalonia, Spain

${ }^{37}$ Department of Oto-Rhino-Laryngology, University of Kinshasa, Congo

${ }^{38}$ European Federation of Allergy and Airways Diseases Patients' Associations (EFA), Brussels, Belgium

${ }^{39}$ Hospital de Egas Moniz and Hospital da Luz, Lisbon, Portugal

${ }^{40}$ ENT department, University Hospital of Liege, Belgium

${ }^{41}$ Department of Otorhinolaryngology, University of Crete School of Medicine, Greece

${ }^{42}$ Center of Allergy \& Environment (ZAUM), Technical University and Helmholtz Center Munich, Munich, Germany

${ }^{43}$ Centre of Microbial and Plant Genetics, KU Leuven, Leuven, Belgium

${ }^{44}$ Lithuanian Universitys of health sciences, Department of Immunology and allergology, Kaunas, Lithuania

${ }^{45}$ Department of Otorhinolaryngology, Oslo University Hospital - Rikshospitalet, Oslo, Norway

${ }^{46}$ Private practice, Antwerpen, Belgium

${ }^{47}$ ALK, The Netherlands

${ }^{48}$ Department of Otorhinolaryngology, Sint-Jozefskliniek, Izegem, Belgium

${ }^{49}$ Department of Otorhinolaryngology and Head and Neck Surgery, Helsinki University Hospital, Helsinki, Finland

${ }^{50}$ Department of Otorhinolaryngology, AZ St. Johns Hospital, Bruges, Belgium

${ }^{51}$ Department of Otorhinolaryngology, University Hospital Düsseldorf, Düsseldorf, Germany

${ }^{52}$ Comprehensive Allergy-Centre-Charité, Department of Dermatology and Allergy, Charité-Universitätsmedizin Berlin, Germany

\section{Abstract}

The first European Rhinology Research Forum organized by the European Forum for Research and Education in Allergy and Airway Diseases (EUFOREA) was held in the Royal Academy of Medicine in Brussels on 17th and 18th November 2016, in collaboration with the European Rhinologic Society (ERS) and the Global Allergy and Asthma European Network (GA2LEN). One hundred and thirty participants (medical doctors from different specialties, researchers, as well as patients and industry representatives) from 27 countries took part in the multiple perspective discussions including brainstorming sessions on care pathways and research needs in rhinitis and rhinosinusitis. The debates started with an overview of the current state of the art, including weaknesses and strengths of the current practices, followed by the identification of essential research needs, thoroughly integrated in the context of Precision Medicine (PM), with personalized care, prediction of success of treatment, participation of the patient and prevention of disease as key principles for improving current clinical practices. This report provides a concise summary of the outcomes of the brainstorming sessions of the European Rhinology Research Forum 2016.

Key words: care pathway, rhinitis, rhinosinusitis, precision medicine, research 


\section{Introduction}

The first European Rhinology Research Forum (www.rhinologyresearch.eu) organized by the European Forum for Research and Education in Allergy and Airway Diseases (EUFOREA) was held in collaboration with the European Rhinologic Society and the Global Allergy and Asthma European Network (GA2LEN). Brainstorming sessions on care pathways and research needs in rhinitis, rhinosinusitis engaged 130 European medical doctors from different specialties, researchers, as well as patients and industry representatives. The needs were thoroughly discussed in the context of Precision Medicine (PM), with personalized care, prediction of success of treatment, participation of the patient and prevention of disease as key principles for improving current clinical practices. Research in the field of PM in rhinology is supported by EUFOREA, paving the way for a more structured scientific approach for patients with chronic upper airway inflammation.

Within the field of rhinology, inflammatory conditions take a prominent position in daily care. Rhinitis and chronic rhinosinusitis (CRS) are the most prevalent non-communicable chronic diseases with significant burden for the patients and high socioeconomic impact ${ }^{(1-3)}$. Over the past decades, major efforts have been invested in the elaboration of evidence-based treatment guidelines for both allergic rhinitis (AR) and CRS ${ }^{(4,5)}$. Moreover, the possible causal relationship between AR and CRS has been investigated ${ }^{(5)}$.

Rhinitis is an umbrella term that embraces different inflammatory phenotypes: allergic, infectious and other forms of nonallergic, non-infectious rhinitis ${ }^{(6)}$. AR is the best-characterized phenotype, involving type 2 inflammation of the nasal mucosa, giving rise to nasal congestion, rhinorrhoea, sneezing, itchy nose and/or eyes, and nasal hyperreactivity ${ }^{(7,8)}$. Two main pillars of anti-allergic treatment are currently being recommended: symptomatic treatment and allergen-specific immunotherapy (AIT) ${ }^{(9,10)}$. CRS is characterized by inflammation of the paranasal sinus mucosa and can be subdivided into two major clinical phenotypes based on nasal endoscopy: CRS with (CRSwNP) and CRS without (CRSsNP) nasal polyps ${ }^{(11,12)}$. The cornerstone of CRS treatment is prolonged medical anti-inflammatory treatment supplemented by functional endoscopic sinus surgery (FESS) in case of treatment failure.

Given the high prevalence of AR and CRS, cost-effective treatment approaches represent a medical and societal challenge. Based on the principles of Precision Medicine ${ }^{(13-15)}$, the non-profit organization EUFOREA has recently proposed a cost-effective strategy for gradual implementation of the four principles of PM into daily practice (manuscript submitted). Due to cost-effectiveness considerations personalized care including endotypedriven treatment can only be recommended for AR and CRS patients uncontrolled with the current treatment approaches ${ }^{(16,}$ 17). The concept of control has been embraced for both AR and
CRS using easy-to-apply tools, i.e. visual analogue scale (VAS) score for $A{ }^{(18)}$ and a 7-item questionnaire for CRS ${ }^{(5)}$. The brainstorming sessions aimed at discussing the current imperfections and unmet needs in the care pathways in AR and CRS and at highlighting and agreeing on the research priorities in the field.

\section{Optimal care pathways in rhinitis}

\section{Strengths of the current pathways}

Evidence-based care pathways for rhinitis have been developed by ARIA (Allergic Rhinitis and its Impact on Asthma) and other consensus documents ${ }^{(4,19,20)}$. An updated clinical decision algorithm for patients with allergic rhinitis has recently been proposed by MACVIA (Contre les Maladies Chroniques pour un Vieillissement Actif) ${ }^{(18)}$ as part of a clinical decision support system (CDSS) for AR (European Innovation Partnership on Active and Healthy Ageing, DG CONNECT and DG Santé) ${ }^{(19)}$. Assessment of the level of disease control is a key factor to decide upon stepping-up, stepping-down or maintaining the treatment. Current rhinitis care pathways have suggested the VAS as a simple tool to assess disease control ${ }^{(17)}$. Well-controlled AR is defined as a score of $\leq 2$ on 10, whereas a score of 5 or above is pointing towards uncontrolled $A R^{(21,22)}$.

\section{Shortcomings of the current care pathways}

Current care pathways should be continuously re-evaluated and optimized to increase the level of control in rhinitis patients. Different shortcomings were discussed during the brainstorming session (Figure 1):

- Patients mostly self-medicate for AR and rarely follow guidelines. In particular, patients downgrade or interrupt their treatment in parallel with improvement of their symptoms.

- The time for patients with persistent rhinitis symptoms to enter the care pathway is often delayed. This has a major impact since disease control is most likely achieved by an adequate early diagnosis and optimal treatment advice with initiation of prevention strategies. Under-diagnosis of AR is a fact in $50 \%$ of patients; especially the adolescent and young adults may not perceive correctly the chronic nature of the disease ${ }^{(23,24)}$. In addition, prejudices or false beliefs of the patient on the treatment for AR impact optimal care $(25,26)$. Therefore, patient education is an essential step in achieving optimal control of rhinitis. Online information is often the first source of information for a patient with nasal symptoms. Unfortunately, there is no quality check on all information available online, which holds a major risk for the patient. The implementation of an online educational patient platform was identified as one possible tool for EUFOREA to increase disease awareness while correctly informing patients about disease control with proper use of their medication and preventive measures. 


\section{CARE PATHWAYS IN RHINITIS}

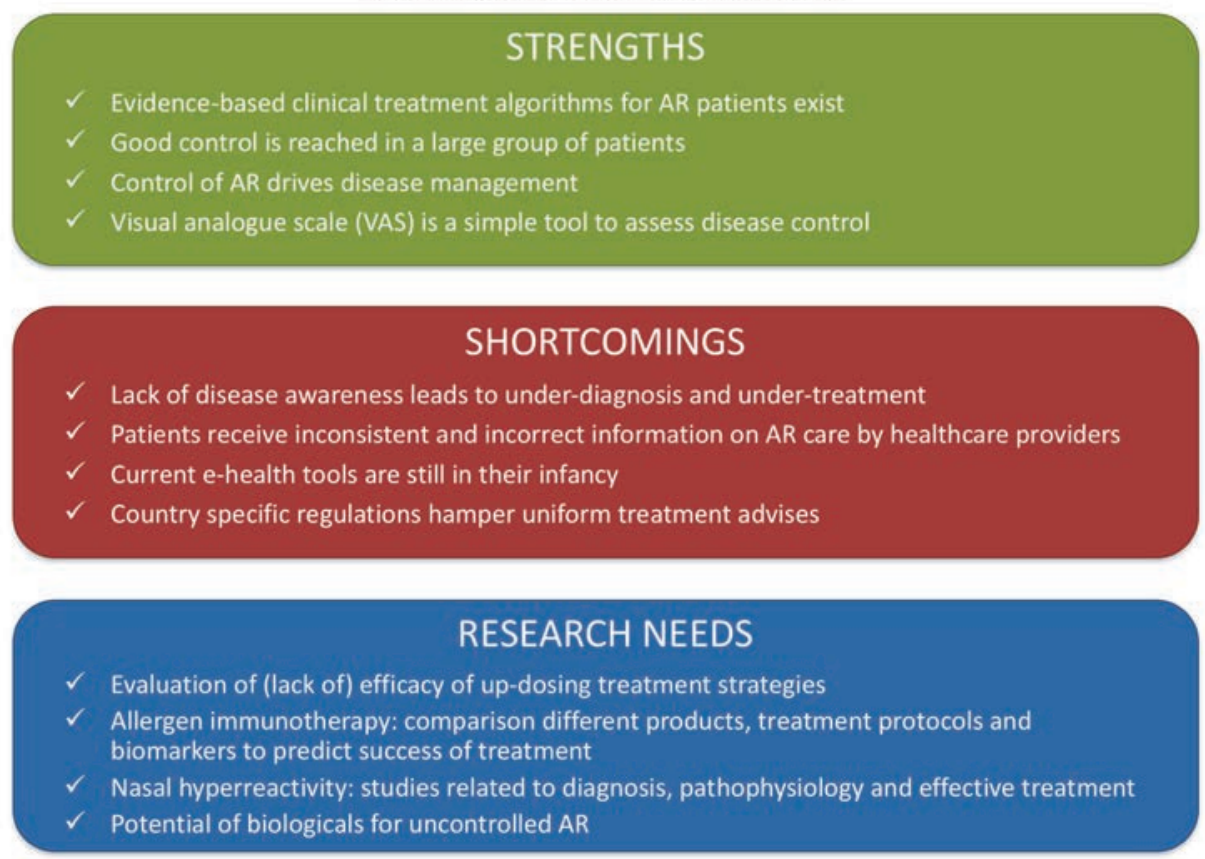

Figure 1. Care pathways in rhinitis.

- Few e-health tools have been developed in the field of rhinology and most are still in their infancy and currently show major shortcomings. Recently, the mobile application - MASK-rhinitis - has been developed for daily monitoring of rhinitis control by assessing VAS scores for various nasal symptoms ${ }^{(27)}$. Future technological development will allow patients to be alerted when medical advice is needed. A companion App on tablet is available to assist physicians in the process of clinical decision-making by providing more precise information on the patients' level of control over time. Data collected on work productivity, treatments efficacy, and treatments adherence will help to improve the optimal care pathway of AR.

- Healthcare professionals at different levels of the care pathway dealing with AR may not always provide consistent information to patients, and different languages and messages on efficacy, safety and adverse events will negatively impact treatment adherence and level of control. Therefore, an integrated care approach ensuring consistency in patient management at all levels needs to be implemented as soon as possible.

- In some countries, the community pharmacist may be the first encounter for patients with upper airway symptoms. Therefore, the pharmacist may need some help to diagnose this highly prevalent condition ${ }^{(28,29)}$. ARIA in the pharmacy has developed an AR diagnostic tool, which should be better deployed and digitalized.

- Designing uniform optimal care pathways across Europe are often hampered by country specific regulations or unavailability of the best treatment to all patients. A common European approach, based on an optimized and cost-effective care pathway should therefore be created in cooperation with European policy makers ${ }^{(19)}$.

- The position of allergen immunotherapy (AIT) in the optimal care pathway for AR is still a matter of debate. In the clinical decision support system (CDDS) making algorithms, AIT is considered when a patient remains uncontrolled despite maximal pharmacological treatment ${ }^{(18)}$. AIT may prevent development of new sensitizations ${ }^{(30,31)}$, asthma and widening of the spectrum of allergy ${ }^{(30,32)}$. It requires further study to determine whether progression of disease might be prevented by the early introduction of AIT in the optimal care pathway ${ }^{(33)}$.

\section{Research needs in the current care pathways}

The following research needs have been highlighted during the brainstorming session on care pathways in rhinitis (Figure 1):

- Patients with AR often self-medicate but there is no general accepted recommendation and under-treatment is common.

- Patients with AR are often treated beyond evidence-based guidelines, and there is a need to study the (lack of) efficacy of up-dosing treatment strategies (e.g. with combination treatment of antihistamines and nasal corticosteroids).

- Adherence to medication is a key factor to control AR and there is a need to better understand the fear of AR patients 


\section{CARE PATHWAYS IN RHINOSINUSITIS}

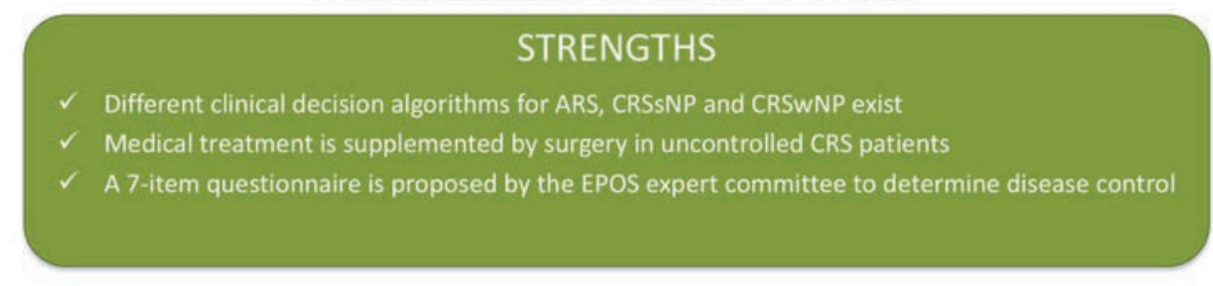

\section{SHORTCOMINGS}

No validation of EPOS criteria for control and of cut off values for VAS to assess control

Co-morbidities are rarely part of an integrated approach

Limited number of biomarkers being clinically relevant

$\checkmark$ Unclear role of CT score vs endoscopic polyp score as indication for sinus surgery

$\checkmark$ No consensus on timing and extent of surgery in relation to disease control and prevention

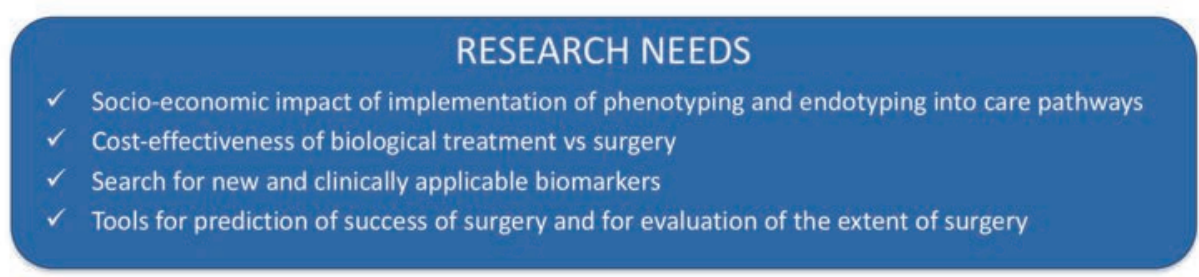

Figure 2. Care pathways in rhinosinusitis.

of using nasal corticosteroids.

- $\quad$ AIT is associated with large number of research needs, such as comparing different products, treatment protocols, and biomarkers to predict the success of AIT.

- Nasal hyperreactivity (NHR) is a major symptom in two thirds of patients with AR and needs to be properly diagnosed and monitored. Research is needed to better understand the diagnosis, pathophysiology and effective treatment.

- Although it is believed that biologicals should be positioned as a treatment option for severe cases of rhinitis when associated with asthma, their efficacy as treatment have not been evaluated yet. However, at the moment due to their costs, it is unlikely that they will have a place in the treatment strategy of rhinitis.

- $\quad$ Research on well-being in patients with rhinitis is essential.

- Implementation of integrated care in rhinitis across the life course is a major goal ${ }^{(34)}$. Rhinitis in elderly adults should be better understood and managed.

- Research on the natural history of AR and CRS is needed.

\section{Optimal care pathways in rhinosinusitis}

Strengths of the current pathways

For CRS, a clinical decision algorithm has been reported in the European position paper on rhinosinusitis and nasal polyps ${ }^{(5)}$. Different algorithms were developed according to the presence of acute (ARS) or chronic (CRS) with (CRSwNP) or without (CRSsNP) the presence of nasal polyps. A 7-item questionnaire based on presence of symptoms, endoscopic findings and need for systemic medication is used to assess the level of control in patients with CRS ${ }^{(5)}$.

A patient with uncomplicated nasal symptoms for less than 7 days should be managed as a common cold as assessed and reported in different Cochrane reviews ${ }^{(35-38)}$. Evaluation of the presence of allergy should be considered when a patient repeatedly consults with ARS ${ }^{(5)}$. Maxillary puncture is still currently performed in a limited number of countries without evidence for its effectiveness.

Diagnosis of CRS is based on the presence of 2 or more symptoms of which one should be nasal obstruction or discolored discharge with or without facial pain, headache or smell disturbance for $\geq 12$ weeks ${ }^{(5)}$.

\section{Shortcomings of the current pathways}

Also for rhinosinusitis there is a need for continuous re-evaluation and optimization of existing care pathways to increase the level of disease control. Different shortcomings were discussed during the brainstorming session (Figure 2):

- Despite the availability of VAS to assess the level of control, its use to define the level of CRS control has not been validated.

- Patients attending a primary care physician often expect antibiotic treatment, even when there is no indication ${ }^{(39,40)}$. Antibiotic resistance and disturbance of the upper airway microbiome are two major risks of unnecessary antibiotic treatment. However, the physicians and the patients are of- 
ten unaware of this or do not realize the importance. There is a need for an online educational platform to inform both patients and health care professionals about these issues.

- Co-morbidities are rarely part of the integrated approach for CRS. Careful assessment of the etiologic factors and co-morbidities should be considered at the secondary and tertiary level of care, including smoking, the presence of allergy, occupational factors (e.g. allergy against low molecular weight agents), asthma, aspirin-intolerance, immune deficiency, polyps, calcifications and/or osteoneogenesis on CT (as signs of more severe disease), and cystic fibrosis or primary ciliary dyskinesia ${ }^{(5)}$.

- A limited number of biomarkers are currently available for clinical use. Several potential biomarkers might be used for the endotyping of CRS patients: eosinophils in blood, total IgE, specific lgE (e.g. Aspergillus fumigatus), Staphylococcus enterotoxin specific lgE, eosinophil cationic protein $(E C P)$, eosinophil mucin or total lgE in nasal secretions, and periostin in serum ${ }^{(11,41)}$. The first three biomarkers were recommended in the brainstorming sessions for patients with severe nasal polyps persisting after maximal medical treatment. The expression level of these biomarkers has a direct impact on the treatment schemes. Other biomarkers could be used to monitor novel biological treatments; however, these drugs are currently not yet available for patients with nasal polyps without severe asthma. Clinically applicable and validated biomarkers need to be developed by the time biologicals become available for patients with CRS (42-44).

- The role of CT score versus endoscopic polyp score as an indication for sinus surgery is still a matter of debate. Recently, a Delphi approach was used to define indications for surgery in patients with uncomplicated CRSsNP and CRSWNP (45).

- $\quad$ For CRSsNP a CT score (Lund-Mackay score) $\geq 1$ and a SNOT (SinoNasal Outcome Test) score $\geq 20$ after medical treatment consisting of at least 2 months of topical intranasal corticosteroid plus either a short course of broad-spectrum/culture-directed systemic antibiotic (2 to 3 weeks duration) or a prolonged course (12 weeks duration) of systemic low-dose anti-inflammatory antibiotic (i.e., macrolide or cotrimoxazol).

- For CRSwNP a CT (Lund-Mackay score) score $\geq 1$ and a SNOT score $\geq 20$ after medical treatment consisting of at least 2 months of topical intranasal corticosteroid plus a short-course (1 to 3 week duration) of systemic corticosteroid.

For CRSwNP, the use of an endoscopic polyp score of at least 3 on both sides ( 1 at one side and 2 at the other side) was considered by the brainstorming group as more suitable than a CT score $\geq 1$ as part of indications for surgery.
In addition, whether or not to perform surgery should be discussed with the patient and the patients' opinion should be taken into account. A patient has always the right to decline surgery; however the patient cannot decide to get surgery if there is no indication.

\section{Research needs of the current pathways}

- Maxillary puncture for acute rhinosinusitis is currently only being performed in a limited number of countries because there is no evidence to prove that it is effective. Clinicians from those countries should therefore be encouraged to set up studies to evaluate whether puncture reduces pain in the acute phase.

- $\quad$ Phenotyping and endotyping ${ }^{(46)}$ are the way forward to improve the level of control of CRS patients. A number of research needs are associated with this:

- It is not clear which phenotyping and endotyping should be implemented at different levels of the care pathway.

- Studies looking at cost-effectiveness and the socio-economic impact of implementation of phenotyping and endotyping into care pathways are needed.

- There is a need for clinically applicable biomarkers for identification of a patient's endotype.

- Up to $40 \%$ of CRS patients remain uncontrolled despite sinus surgery ${ }^{(47,48)}$. Although CRSwNP patients have higher percentages of revision surgery than CRSsNP ${ }^{(49)}$ the degree of control post-surgery is similar for both groups ${ }^{(47,48)}$. There is a need for:

- Tools to predict success of surgery.

- Evaluation of the position of surgery versus medical treatment.

- $\quad$ Evaluation on when to perform revision surgery ${ }^{(50)}$.

- Biological treatment will become available for patients with CRSwNP in the next decade. The position of biologicals in the current care pathways is not clear at this moment:

- How to identify patients eligible for biological treatments?

- How to choose between different biological treatments?

- Position of biological treatment versus surgery or oral corticosteroids.

- Strategies to improve patient compliance need to be elaborated.

- Real life studies evaluating and validating cut off levels for VAS or other measurements of control should be performed.

\section{Research needs in rhinology}

Evidence-based guidelines for treatment of rhinitis and rhinosinusitis exist, however some shortcomings are recognized as areas for improvement. Implementation of these guidelines 


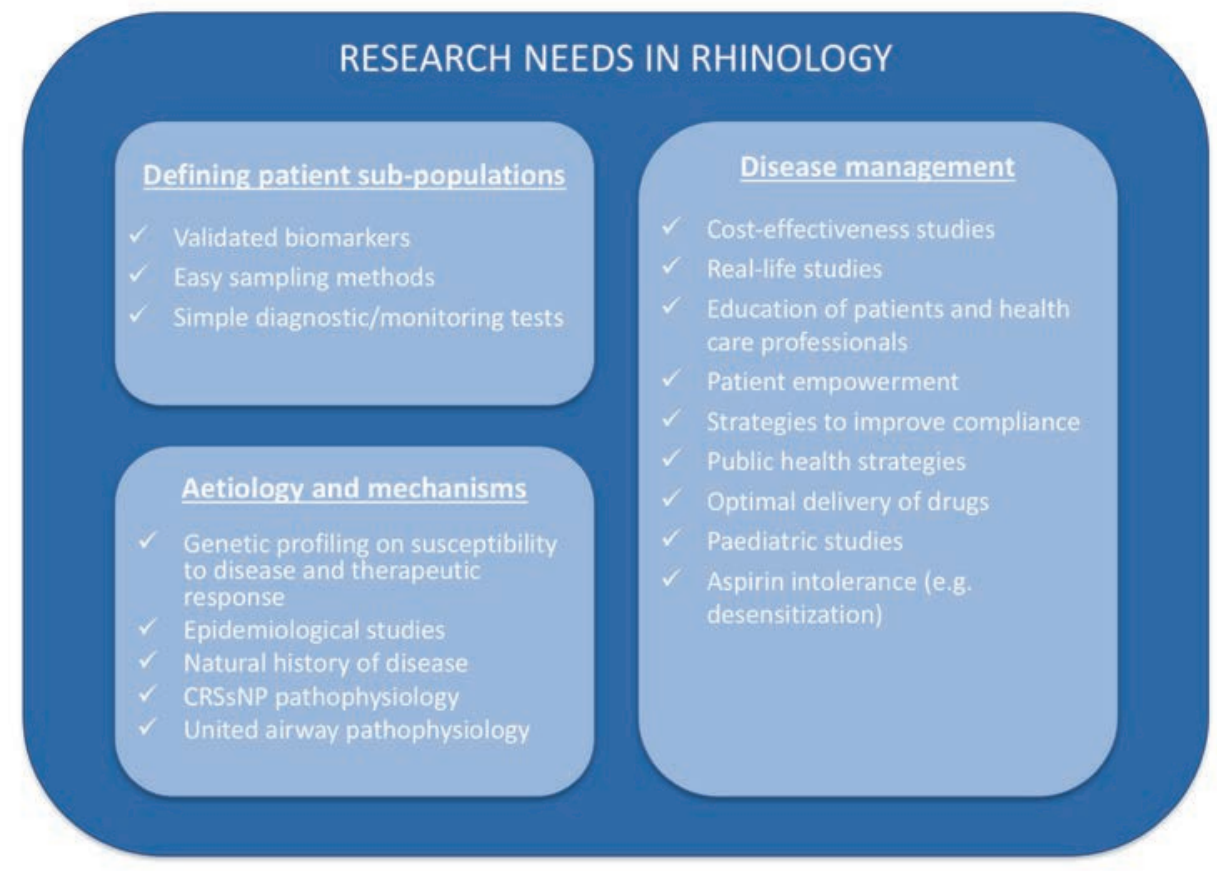

Figure 3. Research needs in rhinology.

into clinical practice is crucial but still little is done. Use of care pathways, modern technology and a patient-centered approach are most likely to change the management of upper airway diseases. Patient empowerment and self-management represent two major avenues for research. The ultimate goal of a costeffective management will be well-being with nasal diseases.

Cross-specialty collaboration is warranted to achieve uniformity among guidelines (primary care physician, ENT specialist, chest physician, allergist, community pharmacist, allied health).

The research needs in rhinology agreed upon during the brainstorming session are summarized in Figure 3 . These could be subdivided into three categories:

- Defining patient sub-populations.

- Disease aetiology and mechanisms.

- Management of uncontrolled patients.

In addition, some general principles related to research in rhinology were discussed during the brainstorming session:

- Interdisciplinary collaboration is needed.

- Publication of negative as well as positive studies should be stimulated in order to have a better understanding of the efficacy and safety of interventions in AR and CRS.

- Quantitative research in real-life studies evaluating large number of patients should be reinforced.

- Application of health information technology for data collection, real-time analysis and feedback for CDSS and for education should be available for all stakeholders, including patients, researchers, clinicians, administrators, and politicians.

- Setup of biobanks for biomarker mining and rapid validation of novel candidates.

\section{Conclusion}

The brainstorming sessions of the European Rhinology Research Forum were conceived to facilitate a collaborative effort to identify the unmet needs in regards to the optimal care pathways in rhinitis and rhinosinusitis. Building research networks and thereby open doors for synergistic multicenter research emerged as top priority. A research support platform is currently being installed by EUFOREA with the aim to support joint research efforts in the field of upper airway diseases and beyond.

The second edition of the European Rhinology Research Forum will be held in November 2017 (www.rhinologyresearch.eu).

\section{Authorship contribution}

PWH, WJF: design the brainstorming session and writing the manuscript.

SS: writing the manuscript.

others: contribution to brainstorm sessions and reviewing of the manuscript.

\section{Conflict of interest}

No conflict of interest. 


\section{References}

1. Canonica GW, Bousquet J, Mullol J, Scadding GK, Virchow JC. A survey of the burden of allergic rhinitis in Europe. Allergy. 2007;62 Suppl 85:17-25.

2. Greiner AN, Hellings PW, Rotiroti G, Scadding GK. Allergic rhinitis. Lancet. 2011;378:2112-22.

3. Hastan D, Fokkens WJ, Bachert C, Newson RB, Bislimovska J, Bockelbrink A, et al. Chronic rhinosinusitis in Europe--an underestimated disease. A GA²LEN study. Allergy. 2011;66:1216-23.

4. Bousquet J, Khaltaev N, Cruz AA, Denburg J, Fokkens WJ, Togias A, et al. Allergic Rhinitis and its Impact on Asthma (ARIA) 2008 update (in collaboration with the World Health Organization, GA(2)LEN and AllerGen). Allergy. 2008;63 Suppl 86:8-160.

5. Fokkens WJ, Lund VJ, Mullol J, Bachert C, Alobid I, Baroody F, et al. European Position Paper on Rhinosinusitis and Nasal Polyps 2012. Rhinology Supplement. 2012:3 p preceding table of contents, 1-298.

6. Papadopoulos NG, Bernstein JA, Demoly P, Dykewicz M, Fokkens W, Hellings PW, et al. Phenotypes and endotypes of rhinitis and their impact on management: a PRACTALL report. Allergy. 2015;70:474-94.

7. Bousquet J, Van Cauwenberge P, Khaltaev N, Group AW, Organization WH. Allergic rhinitis and its impact on asthma. J Allergy Clin Immunol. 2001;108:S147-334.

8. Segboer $C L$, Holland $C T$, Reinartz $S M$, Terreehorst I, Gevorgyan A, Hellings PW, et al. Nasal hyper-reactivity is a common feature in both allergic and nonallergic rhinitis. Allergy. 2013;68:1427-34.

9. Droessaert $V$, Timmermans $M$, Dekimpe $E$, Seys S, Ceuppens JJ, Fokkens WJ, et al. Reallife study showing better control of allergic rhinitis by immunotherapy than regular pharmacotherapy. Rhinology. 2016;54:21420.

10. Jutel M, Agache I, Bonini S, Burks AW, Calderon M, Canonica W, et al. International consensus on allergy immunotherapy. J Allergy Clin Immunol. 2015;136:556-68.

11. Bachert C, Akdis CA. Phenotypes and Emerging Endotypes of Chronic Rhinosinusitis. J Allergy Clin Immunol Pract. 2016:4:621-8.

12. Lou H, Meng Y, Piao Y, Zhang N, Bachert C, Wang C, et al. Cellular phenotyping of chronic rhinosinusitis with nasal polyps. Rhinology. 2016;54(2):150-9.

13. Collins FS, Varmus $H$. A new initiative on precision medicine. N Engl J Med. 2015;372(9):793-5.

14. Muraro A, Fokkens WJ, Pietikainen S, Borrelli D, Agache I, Bousquet J, et al. European symposium on precision medicine in allergy and airways diseases: report of the European Union parliament symposium (October 14, 2015). Rhinology. 2015;53(4):303-7

15. Muraro A, Fokkens WJ, Pietikainen S, Borrelli D, Agache I, Bousquet J, et al. European
Symposium on Precision Medicine in Allergy and Airways Diseases: Report of the European Union Parliament Symposium (October 14, 2015). Allergy. 2016;71(5):5837.

16. Bousquet J, Bachert C, Canonica GW Casale TB, Cruz AA, Lockey RJ, et al. Unmet needs in severe chronic upper airway disease (SCUAD). J Allergy Clin Immunol. 2009; 124:428-33.

17. Hellings PW, Fokkens WJ, Akdis C, Bachert C, Cingi C, Dietz de Loos D, et al. Uncontrolled allergic rhinitis and chronic rhinosinusitis: where do we stand today? Allergy. 2013;68:1-7

18. Bousquet J, Schünemann HJ, Hellings PW, Arnavielhe S, Bachert C, Bedbrook A, et al. MACVIA clinical decision algorithm in adolescents and adults with allergic rhinitis. J Allergy Clin Immunol. 2016;138:367-74.e2.

19. Bousquet J, Addis A, Adcock I, Agache I, Agusti A, Alonso A, et al. Integrated care pathways for airway diseases (AIRWAYSICPS). Eur Respir J. 2014;44(2):304-23.

20. Roberts $G$, Xatzipsalti $M$, Borrego LM, Custovic A, Halken S, Hellings PW, et al. Paediatric rhinitis: position paper of the European Academy of Allergy and Clinical Immunology. Allergy. 2013;68:1102-16.

21. Bousquet PJ, Combescure C, Neukirch F, Klossek JM, Méchin H, Daures J-P, et al. Visual analog scales can assess the severity of rhinitis graded according to ARIA guidelines. Allergy. 2007;62:367-72.

22. Demoly P, Bousquet PJ, Mesbah K, Bousquet J, Devillier P. Visual analogue scale in patients treated for allergic rhinitis: an observational prospective study in primary care: asthma and rhinitis. Clin Exp Allergy. 2013:43:881-8.

23. Jacobs TS, Forno E, Brehm JM, Acosta-Pérez E, Han Y-Y, Blatter J, et al. Underdiagnosis of allergic rhinitis in underserved children. J Allergy Clin Immunol. 2014;134:737-9.e6.

24. Occasi F, Duse M, Vittori T, Rugiano A, Tancredi G, De Castro G, et al. Primary school children often underestimate their nasal obstruction. Rhinology. 2016;54(2):164-9.

25. Hellings PW, Dobbels F, Denhaerynck K, Piessens M, Ceuppens JL, De Geest S. Explorative study on patient's perceived knowledge level, expectations, preferences and fear of side effects for treatment for allergic rhinitis. Clin Transl Allergy. 2012;2:9.

26. Koberlein J, Kothe AC, Schaffert C. Determinants of patient compliance in allergic rhinoconjunctivitis. Curr Opin Allergy Clin Immunol. 2011;11(3):192-9.

27. Bourret R, Bousquet J, Mercier J, Camuzat T, Bedbrook A, Demoly P, et al. MASK-rhinitis, a single tool for integrated care pathways in allergic rhinitis. World Hosp Health Serv. 2015:51:36-9.

28. Lourenço O, Calado S, Sá-Sousa A, Fonseca J. Evaluation of allergic rhinitis and asthma control in a Portuguese community pharmacy setting. J Manag Care Spec Pharm.
2014;20:513-22

29. Workshops Mot. ARIA in the pharmacy: management of allergic rhinitis symptoms in the pharmacy. Allergic rhinitis and its impact on asthma. Allergy. 2004;59:373-87.

30. Jacobsen L, Niggemann B, Dreborg S, Ferdousi HA, Halken S, Høst A, et al. Specific immunotherapy has long-term preventive effect of seasonal and perennial asthma: 10-year follow-up on the PAT study. Allergy. 2007;62:943-8.

31. Di Bona D, Plaia A, Leto-Barone MS, La Piana S, Macchia L, Di Lorenzo G. Efficacy of allergen immunotherapy in reducing the likelihood of developing new allergen sensitizations: a systematic review. Allergy. 2017 May:72(5):691-704.

32. Cardona V, Luengo O, Labrador-Horrillo M. Immunotherapy in allergic rhinitis and lower airway outcomes. Allergy. 2017;72(1):35-42.

33. Calderon MA, Demoly P, Casale T, Akdis CA, Bachert C, Bewick M, et al. Allergy immunotherapy across the life cycle to promote active and healthy ageing: from research to policies: An AIRWAYS Integrated Care Pathways (ICPS) programme item (Action Plan B3 of the European Innovation Partnership on active and healthy ageing) and the Global Alliance against Chronic Respiratory Diseases (GARD), a World Health Organization GARD research demonstration project. Clin Transl Allergy. 2016;6:41.

34. Bousquet J, Farrell J, Crooks G, Hellings P, Bel $\mathrm{EH}$, Bewick M, et al. Scaling up strategies of the chronic respiratory disease programme of the European Innovation Partnership on Active and Healthy Ageing (Action Plan B3: Area 5). Clin Transl Allergy. 2016;6:29.

35. De Sutter AIM, Saraswat A, van Driel $M L$. Antihistamines for the common cold. Cochrane Database Syst Rev. 2015:CD009345.

36. Deckx L, De Sutter Al, Guo L, Mir NA, van Driel ML. Nasal decongestants in monotherapy for the common cold. Cochrane Database Syst Rev. 2016;10:CD009612.

37. Hayward G, Thompson MJ, Perera R, Del Mar CB, Glasziou PP, Heneghan CJ. Corticosteroids for the common cold. Cochrane Database Syst Rev. 2015:CD008116.

38. King D, Mitchell B, Williams CP, Spurling GKP. Saline nasal irrigation for acute upper respiratory tract infections. Cochrane Database Syst Rev. 2015:CD006821.

39. Fokkens WJ, Hoffmans R, Thomas M. Avoid prescribing antibiotics in acute rhinosinusitis. BMJ. 2014;349:g5703.

40. Sng WJ, Wang DY. Efficacy and side effects of antibiotics in the treatment of acute rhinosinusitis: a systematic review. Rhinology. 2015;53(1):3-9.

41. Vlaminck $S$, Vauterin T, Hellings PW, Jorissen M, Acke F, Van Cauwenberge $P$, et al. The importance of local eosinophilia in the surgical outcome of chronic rhinosinusitis: a 3-year prospective observational study. Am 
J Rhinol Allergy. 2014;28(3):260-4.

42. Bachert C, Mannent L, Naclerio RM, Mullol J, Ferguson BJ, Gevaert P, et al. Effect of Subcutaneous Dupilumab on Nasal Polyp Burden in Patients With Chronic Sinusitis and Nasal Polyposis: A Randomized Clinical Trial. JAMA. 2016:315:469-79.

43. Gevaert P, Calus L, Van Zele T, Blomme K, De Ruyck N, Bauters W, et al. Omalizumab is effective in allergic and nonallergic patients with nasal polyps and asthma. J Allergy Clin Immunol. 2013;131:110-6.e1.

44. Gevaert P, Van Bruaene N, Cattaert T, Van Steen K, Van Zele T, Acke F, et al. Mepolizumab, a humanized anti-IL-5 mAb, as a treatment option for severe nasal polyposis. J Allergy Clin Immunol. 2011;128:98995.e1-8.

45. Rudmik L, Soler ZM, Hopkins C, Schlosser RJ, Peters A, White AA, et al. Defining appropriateness criteria for endoscopic sinus sur- gery during management of uncomplicated adult chronic rhinosinusitis: a RAND/ UCLA appropriateness study. Rhinology. 2016:54:117-28.

46. Tomassen P, Vandeplas G, Van Zele T, Cardell L-O, Arebro J, Olze H, et al. Inflammatory endotypes of chronic rhinosinusitis based on cluster analysis of biomarkers. J Allergy Clin Immunol. 2016:137:1449-56.e4.

47. Kohli P, Soler ZM, Storck KA, Shahangian A, Banglawala SM, Schlosser RJ. Responsiveness and reliability of the Sinus Control Test in chronic rhinosinusitis. Rhinology. 2017 Mar 1;55(1):39-44.

48. van der Veen J, Seys SF, Timmermans M Levie P, Jorissen M, Fokkens WJ, et al. Reallife study showing uncontrolled rhinosinusitis after sinus surgery in a tertiary referral centre. Allergy. 2017;72(2):282-290.

49. Hopkins C, Slack R, Lund V, Brown P, Copley $L$, Browne J. Long-term outcomes from the
English national comparative audit of surgery for nasal polyposis and chronic rhinosinusitis. Laryngoscope. 2009;1 19(12):245965.

50. Rudmik L, Soler ZM, Hopkins C. Using postoperative SNOT-22 to help predict the probability of revision sinus surgery. Rhinology. 2016;54(2):111-6.

\section{Sven Seys \\ EUFOREA}

Brand Whitlocklaan 132

1300 Brussels

Belgium

E-mail: sven.seys@euforea.eu

\section{ADVERTISEMENT}

EUROPEAN RHINOLOGY RESEARCH FORUM 